\title{
AS INVASÕES DE CÉSAR À BRETANHA REPERCUTEM NO SENADO ROMANO: UMA ANÁLISE DAS CARTAS DE CÍCERO (Q FR II, 15; Q FR III, 1; FAM. VII, 5; FAM. VII, 7)
}

\author{
CAESAR'S INVASIONS OF BRITAIN REVERBERATE IN ROMAN \\ SENATE: AN ANALYSIS OF CICERO'S LETTERS \\ (Q FR II, 15; Q FR III, 1; FAM. VII, 5; FAM. VII, 7)
}

DOI: http://dx.doi.org/10.15448/2178-3748.2016.1.20311

\author{
Dominique Santos 1 \\ Doutor em História - Universidade de Blumenau \\ dvcsantos@furb.br
}

Helena Schütz Leite Graduanda em História - Universidade de Blumenau helena.schutzleite@gmail.com

\begin{abstract}
RESUMO: A narrativa central das invasões dos romanos à Bretanha, que aconteceram entre os anos 55 e 54 a.C, pode ser encontrado na obra De Bello Gallico, escrita pelo próprio general que conduziu a expedição, Cáio Júlio César. Provavelmente, esta obra teve como função fazer com que as notícias concernentes a estes feitos chegassem ao Senado romano. Uma vez tendo cumprido esta função, algumas personagens importantes na política romana debateram a questão ou se posicionaram sobre a mesma, dentre elas Cícero. O principal objetivo deste artigo é tentar perceber um pouco desta repercussão das incursões de César à Bretanha a partir de algumas cartas escritas e enviadas por Marco Túlio Cícero, principal adversário de César. As quatro cartas que serão analisadas aqui foram escolhidas, dentro de um grande número existente, devido principalmente a nossa delimitação temporal, as invasões da Bretanha. Sendo assim, estas epístolas possuem informações significativamente mais relevantes sobre nosso objeto de estudo, porém, o auxilio de outras cartas fez-se também necessário para demonstrar diferentes aspectos da relação de César e Cícero.
\end{abstract}

PALAVRAS-CHAVE: César. Senado Romano. Cartas de Cícero.

ABSTRACT: The main story of the Roman invasion of Britain, which took place between the years 55 and 54 BC, can be found at De Bello Gallico, written by the general who led the expedition, Gaius Julius Caesar. Probably this work's aim was to inform the Roman Senate about the facts that transpired in those expeditions. Once it happened, some important people in Roman politics debated the issue or took a side on it, among them Cicero. This article purpose is to comprehend a little of this repercussion of Caesar's incursions into Britain from some letters written and sent by Marcus Tullius Cicero, the main opponent of Caesar. The four letters that will be analyzed in here were chosen, within a large existing number, mostly because of our time delimitation, the invasions of Britain. Thus, these epistles have significantly more relevant information about our object of study, however, the assistance of other letters was necessary to demonstrate different aspects of Caesar and Cicero's relationship.

KEYWORDS: Caesar, Roman Senate, Cicero's letters.

\section{INTRODUÇÃO}

\footnotetext{
${ }^{1} \mathrm{O}$ artigo em questão foi possível graças ao projeto de pesquisa 39/2014, intitulado: Entre Biografia e História Reflexões sobre a vida de Júlio César a partir das obras: Comentarii de Bello Civilli, Comentarii de Bello

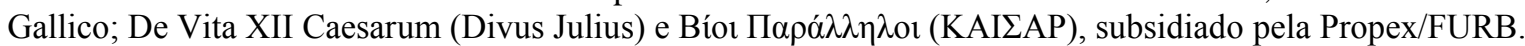


No ano de 55 a.C., Júlio César invade, pela primeira vez, a Bretanha. Tendo boa parte de sua frota naval danificada por uma forte tempestade, permanece na Ilha por alguns dias, sendo constantemente atacado pela população local. Quando consegue recuperar alguns de seus navios, retorna ao continente. No ano seguinte, 54 a. C., ocorre a segunda empreitada do exército romano à Bretanha, dessa vez sem tantos empecilhos da natureza. Na ocasião, César leva consigo cinco legiões e cerca de 600 navios adaptados para as condições marítimas da região. Após enfrentar algumas etnias locais, geralmente descritas como valentes, César obtém a vitória. Ana Teresa Marques Gonçalves (2002, p. 22) afirma que tal representação, como ocorre com os bretões, por exemplo, tem como objetivo enfatizar algumas características particulares do povo retratado, principalmente aquelas relacionadas com a força, coragem, crueldade e a recusa a se render, pois, assim sendo, isto valorizaria a supremacia romana. Ou seja, o poderio romano está justamente em saber se relacionar com estas situações adversas e se sobresair perante um inimigo também poderoso. Depois que César enfrenta e vence, então, esses valorosos povos, ele parte sem deixar guardas na Ilha, apenas impondo tributos.

Esses relatos podem ser encontrados na obra De Bello Gallico, formada por oito livros, sendo os sete primeiros escritos pelo próprio César, e o oitavo por um de seus legados, Aulo Hírcio. Não há um consenso sobre a data de publicação desses escritos, mas Claudia Beltrão da Rosa (2007, p. 40) afirma que o momento mais provável para a redação do mesmo tenha sido o outono de 52 a. C., pois, até então, o público romano conhecia as campanhas apenas por meio de relatos esporádicos, ora muito zelosos da imagem de César, ora maledicentes. Independente disto, o que sabemos é que estas investidas de César à Bretanha causaram profunda comoção no Senado Romano e o tema foi motivo de debate entre os membros que o compunham, sendo considerado de muita importância para alguns, tanto que, ao final da primeira incursão, por exemplo, o Senado declarou vinte dias de Supplicatio, uma demonstração pública de agradecimento pela conquista militar alcançada.

César nasceu no ano 100 a. C.. Como mandava o Cursus Honorum, com 30 anos de idade ele foi eleito Questor ${ }^{2}$. Depois disso foi Edil, Pontifex Maximus, Pretor, Governador da Hispânia Ulterior, da Gália e da Ilíria, foi Cônsul por duas vezes, Ditador (dictator) em 46 a. C. e Ditador Perspétuo (dictator perpetuus) em 44 a. C., ano em que foi assassinado. Durante

\footnotetext{
${ }^{2}$ Os cargos ocupados por César durante sua vida possuem cada qual uma função específica, sendo essas magistraturas de grande importância para o crescimento do cidadão romano em sua vida política. Para uma leitura mais detalhada de tais funções, indicamos: MENDES, Norma Musco. Roma Republicana. São Paulo: Editora Ática S.A., 1988. Obra que trabalha de maneira resumida com as dinâmicas da República romana.
} 
todo este período César conviveu com várias pessoas de natureza distinta e inúmeras situações políticas. Assim, mesmo falar de um Senado nos tempos de César é uma tarefa complexa.

Sabemos que havia neste período da história romana dois grupos políticos, um representado por Sila e outro por Mário. Plutarco nos conta que quando Júlia, a mulher de Mário, morreu, César proferiu um discurso em praça pública em louvor desta e ao final exibiu estátuas de Mário que, nesta ocasião, “foram vistas pela primeira vez desde a Vitória de Sila, porque Mário e todos os seus companheiros tinham sido julgados e declarados inimigos do governo". Mas as ações políticas do tempo de César eram praticadas por inúmeros sujeitos. Lendo as fontes é possível perceber inúmeras destas participações.

A partir de Plutarco, por exemplo, sabemos que César defendeu Lêntulo e Cétego quando Cícero os propôs matar, o que levou Catão a acusá-lo de conspirador, junto, então, com Catilina; que certa vez quando César saia do Senado foi acompanhado por um grupo dos rapazes de Cícero que por pouco não o mataram; que deu sua filha Júlia em casamento para Pompeu a fim de estabelecer com este um vínculo político; que César recorreu a Crasso quando precisou de dinheiro emprestado; que teve como companheiro de Consulado o indesejado Bíbulo, dentre outras coisas mais.

Suetônio, por sua vez, aponta outros acontecimentos, como por exemplo, que César havia sido suspeito, pouco antes de investir no cargo de Edil, de formar uma conspiração contra o Senado, ao lado de Marco Crasso, Públio Sila e Lúcio Antônio; que César haveria acusado de crime de alta traição a Caio Rabírio e, sendo escolhido como juiz para o caso, condenado Rabírio com grande paixão. Já no tempo de seu consulado, após ouvir as lamentações de Cícero sobre a "infelicidade dos tempos" (SUETÔNIO, Vida de César, XX), César decide transferir Clódio, inimigo do orador, da ordem do patriciado para a da plebe.

Outro que nos serve de base para compreensão da história romana do período é Salústio. Ao relatar os acontecimentos da conjuração de Catilina, ele afirma que Q. Cátulo e C. Pisão não puderam fazer com que Cícero envolvesse falsamente César no crime de Catilina. O escritor também pontua que esse processo foi um dos grandes motivos pelo qual o consulado foi oferecido a Cícero, pois sem isso, muitos da nobreza não cogitavam seu nome para o cargo (SALÚSTIO, 49).

Além destes inúmeros entrelaçamentos envolvendo as elites políticas de Roma, a participação popular também com frequência se fazia notar. Apiano, no livro II das Guerras Civis, afirma que César, mesmo quando jovem, era poderoso nas palavras e nas ações, audacioso em tudo e que encontrou maneiras de aparecer aprazível para a multidão (APIANO, Livro II. 1). As ações políticas desenvolvidas no contexto de César, de uma 
maneira ou de outra, precisavam considerar também interesses populares. Quando comenta sobre a conspiração mais importante de seu tempo, Apiano menciona que César não estava livre da suspeita de ter participado desta tentativa de intervenção na política romana liderada pelo já mencionado Catilina, no entanto, ao narrar sobre os interesses que Cícero teria nesta questão, o escritor romano menciona que Cícero "não quis trazer esta controvérsia à tona contra uma pessoa tão aclamada entre o povo" (APIANO, Livro II. 6). Dion Cássio (Roman History, Livro XXXVII. 37) também faz referências a estas intervenções. De acordo com ele, o apoio popular foi fundamental para que César atingisse seus objetivos de ser eleito como Pontifex Maximus. Ou seja, mesmo diante de alguns dos momentos de maior relevância dentre aqueles debatidos pelo Senado Romano, as relações entre o povo e os homens públicos eram fundamentais no momento em que decisões importantes eram tomadas.

Assim, de acordo com a narrativa plutarquiana, os escritos de Suetônio, Apiano, Dion Cássio e Salústio, podemos perceber que o período do final da República romana foi de grande instabilidade política. O Senado já não possuía mais estrutura para controlar uma sociedade que tendia cada vez mais para a expansão. Grupos e clientelas ganhavam mais e mais força no âmbito político romano. Segundo Norberto Luiz Guarinello (2002, p. 14), os senadores gozavam de um vasto poder e utilizavam as diversas clientelas políticas para monopolizar as magistraturas e os governos provinciais. Assim sendo, a influência do Senado em todo o período da República romana foi ampla. Era ele que, basicamente, direcionava os diversos setores da administração pública e, dentre eles, a política externa. Guarinello afirma ainda que "à época de César já não era possível resolver esses choques politicamente [...]. A cidadania dividira-se em partes, em facções organizadas como vastas clientelas que lutavam por seus interesses particulares, sem conseguir um meio termo que atendesse a todos, populares e poderosos.” (GUARINELLO, 2002, p. 14). Os relacionamentos de César com o Senado Romano eram, então, os mais variados possíveis. Se tinha seus partidários, seus desafetos também não eram em pequena quantidade, Marcelo e Lêntulo, por exemplo, o odiavam, um sentimento que era compartilhado também por Catulo, Piso e, possivelmente, Cícero.

\section{MARCO TÚLIO CÍCERO}

O Senado era uma das mais importantes instituições romanas, tendo perdurado desde os tempos da Monarquia, passando pela República, na qual, segundo Norma Musco Mendes 
(1988, p. 31), esteve em destaque no controle do Estado e na sociedade romana. Também passou pelos tempos dos imperadores, bem como pela desagregação deste mesmo Império. Isto significa que esta instituição política durou desde os primeiros tempos que se seguiram a 753 a.C., data tradicional relacionada com a fundação da cidade de Roma, até bem depois de 476 d.C., período que costuma aparecer na historiografia como importante no processo de desagregação do Império Romano do Ocidente. Isto, claro, deixando de lado uma reflexão mais pormenorizada sobre a utilização de todas estas formas para explicar os fenômenos históricos, bem como interpretações que consideram que o Império Romano não teve um fim até 1453. Ou seja, o Senado passou por inúmeras transformações e foi composto e imaginado de diversas maneiras ao longo da história romana. Assim, quando abordamos como as incursões de César à Bretanha repercutem no Senado Romano, é preciso compreender como este era formado no período histórico em questão, quem eram seus membros, quais eram suas atribuições etc. É a partir das cartas de Marco Túlio Cícero, conhecido pela historiografia como filósofo, advogado, escritor, político, e um dos maiores oradores da Antiguidade, que pretendemos compreender a repercussão de tais acontecimentos.

Cícero produziu diversas obras que nos auxiliam a compreender determinados aspectos do contexto da República romana tardia. Apesar destes epítetos, que estão presentes nas próprias fontes ${ }^{3}$ e são reconhecidos até mesmo por inimigos políticos, de forma alguma pretendemos fazer uma história de grandes nomes e heróis ao falar sobre Cícero. Pelo contrário, observamos as reflexões apresentadas pela nova história política, que já não permitem tal idealização (CARDOSO, 2012). Afinal, não podemos interpretar a vida do orador romano como algo designado, a priori, ao sucesso ou fracasso.

Pierre Bourdieu (1996, p. 183-191), acerca dos estudos biográficos, critica severamente o que denomina de "ilusão biográfica", a ação muito comum nas biografias e histórias de vida que considera cada acontecimento como se já estivesse pré-determinado, coerentemente pensado, visando certa finalidade. Reflexão semelhante é apresentada pelo historiador brasileiro Benito Schmidt (2003, p. 61), para quem o exame da vida de uma personagem não pode e não deve fazer desta um herói, mas sim tentar ver nela o homem comum. Cabe ao historiador, portanto, analisar os diversos aspectos que cercam e afetam esta personagem.

Isto não significa diminuir a importância de Cícero, trata-se tão somente de uma tentativa de historicizá-lo e compreendê-lo para além de uma narrativa do tipo wie es

\footnotetext{
${ }^{3}$ Apiano, para citar um exemplo, menciona Cícero como "o orador e o retórico mais eloquente do período". Cf. Apiano, Guerras Civis, Livro II. 2.
} 
eigentlich gewessen ${ }^{4}$. Sendo assim, é necessário abordar não apenas o homem romano, mas também a corrente de relações sociais que existiram ao redor deste.

Cícero nasceu no ano de 106 a.C. na pequena cidade de Arpino, há apenas 100 quilômetros de Roma. Provindo de uma família aristocrática, foi cedo enviado a Roma para receber uma educação adequada. Sua carreira como advogado e orador se iniciou em 81 a.C., porém, foi somente no ano seguinte que ele participou de um caso mais notável, defendendo Sexto Róscio, acusado por Sila, ditador de Roma na época. Após um final bem suscedido para Cícero, este decide partir em exílio, devido a possíveis represálias.

O orador voltou a Roma depois da morte de Sila, ingressando em 75 a.C. na carreira política como Questor. Cinco anos mais tarde foi eleito Edil. Passou a possuir o poder de ser um cidadão romano cum imperium a partir de seu pretorado, em 66 a. C. Foi nesse momento que declarou publicamente seu apoio a Pompeu. Chegou ao auge de sua carreira política ao se tornar Cônsul, em 63 a.C.

Cícero foi um amante fervoroso da constituição republicana e, segundo Marta Várzeas (2010, p. 82), foi para defender e manter essa instituição que propôs o concordia ordinum, um acordo entre os grupos sociais optimates - os nobres e os cavaleiros, detentores de riqueza e com possibilidade de entrada no Senado, e os populares, defensores dos interesses do povo. No entanto, esta foi uma proposta que não foi executada e Cícero sequer ofereceu meios para isso.

O tempo de ambos os indivíduos por nós estudados, César e Cícero, era de grande conturbação para a República, em um curto período de apenas três décadas instauraram-se duas ditaduras, instituição que só era permitida em casos extremos. No ano de 60 a. C. havia quatro grandes nomes disputando o poder na Urbs: Cícero, César, Crasso e Pompeu. A relação entre estes homens públicos era tão conturbada quanto a situação política do período. O Senado, temendo perder o poder que possuía, encarava qualquer iniciativa entre os quatro com grande desconfiança. Estas suspeitas senatoriais se mostraram bastante próximas das ações subsequentes, pois da aliança entre estes políticos surgiu o que ficou conhecido popularmente como o primeiro triunvirato, em 59 a.C., uma tentativa que podemos interpretar como uma subtração cada vez maior da influência do Senado em favor de uma concentração de poder político na figura dos envolvidos. Este foi mais um dos eventos públicos da História Romana que Cícero soube perceber muito bem, tanto que não aceitou participar do mesmo,

\footnotetext{
${ }^{4}$ Ou seja, narrar algo "como realmente aconteceu”. Cf. RANKE, Leopold Von. Geschichte der romanischen und germanischen Völker von 1494 bis 1535. Reimer: Leipzig, 1824.
} 
segundo Várzeas, porque ele desconfiava das intenções de César e encontrava-se inclinado a defender os princípios aristocráticos, então ameaçados.

Com a renovação da aliança, após um período de distanciamento, Cícero decide apoiar César, Pompeu e Crasso, tecendo discursos a favor destes no Senado, e recebendo críticas de oportunismo por causa disto. Este tipo de dinâmica social, numa constante alternância e instabilidade na relação entre diversas personagens também aparecerá nas cartas de Cícero, que analisamos mais adiante.

\section{O GÊNERO EPISTOLAR NA ANTIGUIDADE}

A troca de correspondências ${ }^{5}$ exerceu um grande papel na Antiguidade, constituindo um dos meios de comunicação mais utilizados no período. Sabemos por meio de Plutarco, em sua obra Vidas Paralelas, que quando César voltou para Gália depois de suas primeiras incursões à Bretanha encontrou lá cartas recém-chegadas de Roma pelas quais seus amigos lhe comunicaram sobre a morte de sua filha Júlia, que havia acabado de falecer em decorrência do parto, na casa de Pompeu (PLUTARCO, XXXI). Esta não é a única menção que o escritor grego faz de troca de cartas no período, mas também nos dá conta de outras ocasiões nas quais o envio de cartas servia como ferramenta de comunicação e, também, de negociação. Salústio, em sua obra sobre a conjuração de Catilina, também menciona este formato de correspondência. Ele nos informa que o conspirador, ao se ver acusado, decide partir em exílio e que, já no caminho para Marselha, envia cartas a maioria dos consulares e para os cidadãos mais importantes, informando-os de sua decisão (SALÚSTIO, 34).

Segundo Adolf Deissmann (Apud SOARES, 2013, p. 201), há diferença entre uma "carta" e uma "epístola", a primeira sendo destinada a uma pessoa com o objetivo de reportar algo apenas ao indivíduo ao qual a carta foi endereçada, enquanto que a epístola possuiria o papel de informar um grupo maior de pessoas, ao ser publicada. Um exemplo desta prática é a leitura de diversas cartas no Senado. Encontramos várias referências sobre isto na obra de Salústio. De igual modo, Quinto Horácio Flaco também publicou dois livros com epístolas que abordam diversos assuntos.

\footnotetext{
${ }^{5} \mathrm{O}$ gênero epistolar é a área que engloba obras escritas em formas de cartas, que variam na extensão do texto, mas usualmente possuem uma estrutura comum, no início o nome do remetente e do destinatário e uma saudação, seguido pelo conteúdo da epístola.
} 
A visão de Deissmann atualmente é considerada muito rígida e, por isso, na historiografia atual opta-se por uma visão mais ampla do gênero na Antiguidade, que possuía diversos tipos diferentes de cartas. Para Carolline da Silva Soares (2013, p. 201), não havia na Antiguidade uma preocupação em diferenciar cartas, epístolas ou litterae de outros tipos de correspondência. A autora aponta que, mesmo possuindo características específicas, a abordagem atual nos estudos do gênero epistolar tem buscado analisar as relações existentes entre remetente e destinatário.

Outro ponto importante a destacar é a questão da segurança no envio de cartas. Em uma de suas epístolas, Cícero afirma ter demorado no envio, pois não havia encontrado ninguém confiável para transportá-la. O envio, no caso de indivíduos ricos, poderia ser feito por mensageiros conhecidos como tabellarii, servos ou escravos. Num período de tamanha conturbação política, o receio de cartas caindo em mãos erradas era compreensível.

Cícero foi um grande usuário desse meio de comunicação. De suas cartas nos chegaram cerca de 900, sendo divididas nos seguintes grupos: Epistularum ad Atticum libri XVI (cartas de 68 a 43 a.C.); Epistularum ad familiares libri XVI (de 62 a 43 a.C.); Epistularum ad Quintum libri III (de 60 a 54 a.C.); Epistularum ad Brutum libri II (de 43 a.C.). Possuem caráter variado, em certos momentos adquirindo um tom formal e em outros, mais casual, escritas sem aparente intuito de publicação. De acordo com Jenny Druckenmiller (2007, p. 3-4), apenas algumas cartas parecem ter sido escritas para uma posterior publicação, enquanto que a grande maioria não parece em nenhum sentido exercer a mesma função.

Todavia, Cícero não chegou a publicar nenhuma de suas cartas em vida. A historiografia ciceroniana, embora não nomeie um autor para a publicação de uma de suas coleções, o amigo e editor do orador, Ático, é normalmente considerado como publicador das Epistularum ad Atticum. Tirão, secretário de Cícero, seria responsável pela publicação de três livros com cartas enviadas a Quintos, assim como das Epistularum ad Familiares, que possui 436 cartas, dentre as quais 50 foram escritas por grandes personalidades romanas, como Pompeu e César, e enviadas a Cícero. As quatro cartas que nos propomos a analisar neste artigo fazem parte de duas das coleções citadas acima, Epitularii as Quintus e ad Familiares. Duas destas epístolas são endereçadas para seu irmão Quinto, quando este já estava na Bretanha. Das outras duas, uma delas foi enviada para Trebácio Testa e a outra para o próprio César, na Gália.

O principal relato das invasões dos romanos da Bretanha, que aconteceram entre os anos 55 e 54 a.C., pode ser encontrado na obra De Bello Gallico, escrita pelo próprio general que conduziu a expedição, Cáio Júlio César. Provavelmente, esta obra teve como função fazer 
com que as notícias concernentes a estes feitos chegassem ao Senado romano. Uma vez tendo cumprido esta função, algumas personagens importantes na política romana debateram a questão ou se posicionaram sobre a mesma, dentre elas Cícero. Dentre os vários formatos e gêneros textuais utilizados para expressar suas manifestações e considerações sobre o tema, as cartas estão presentes. Por isso, acreditamos ser possível tentar perceber um pouco desta repercussão das incursões de César à Bretanha a partir de algumas cartas escritas e enviadas por Marco Túlio Cícero, principal adversário de César. É o que fazemos a seguir.

\section{AS CARTAS DE CÍCERO E AS INCURSÕES DE CÉSAR À BRETANHA}

É importante lembrarmos que durante o período da República, o responsável pelas ações militares era o Senado. Assim, era de seu interesse ter conhecimento do que ocorria nas campanhas de seus magistrados. A própria obra de Júlio César possui o caráter de um commentarium, relatório que era enviado costumeiramente ao Senado por todos os generais romanos. Era importante manter o Senado, assim como o povo, informado do que ocorria fora de Roma.

Cícero, devido ao fato de ser integrante do Senado e grande defensor da República, e também por manter uma complicada relação com César, era um possível interessado nas campanhas da Bretanha. O fato de seu irmão, Quinto Túlio Cícero, ser um dos legados de César na segunda invasão à Ilha, apenas acrescenta o nível de interesse que o orador poderia possuir na questão. Vamos analisar, então, por meio destas cartas que Cícero escreveu, como as incursões de César à Bretanha repercutiram no Senado Romano.

Como dito acima, o interesse de Cícero nas campanhas na Bretanha parece ter aumentado quando seu irmão passou a fazer parte do exército de César, em 54 a. C.. Em cartas datadas de um período anterior a esta não encontramos muitas menções às campanhas do general romano. Alguns historiadores, como Alex Nice (2003, p. 85) sugerem que é no decorrer desses anos, 55 e 54 a.C., que a relação entre César e Cícero parece sofrer uma mudança. É possível notar isto em várias cartas, dentre elas uma que foi enviada ao próprio César é bem emblemática. Vejamos o fragmento documental:

Cícero cumprimenta César, imperator. Observe quanto eu me convenci de que você é meu segundo eu, não só em assuntos que me interessam pessoalmente, mas mesmo naqueles que dizem respeito os meus 
amigos. [...] Eu, portanto, lhe envio Trebácio. [...] Eu te peço, querido César, para recebê-lo com tal demonstração de bondade e para concentrar em sua única pessoa tudo o que você pode possivelmente ser, induzido a conceder por minha causa sobre os meus amigos. (ad Fam. VII, 5).

Percebemos no trecho acima uma busca por uma relação mais amistosa entre ambos. Segundo Druckenmiller (2007), a concepção romana de amicitia (amizade) seria muitas vezes algum tipo de aliança útil entre pares, envolvendo também interesses políticos. Aparentemente, é isso que Cícero tenta fazer ao solicitar o auxílio de César na promoção da carreira de seus amigos, como Trebácio. Em carta enviada para Quinto, o orador não apenas incentiva seu irmão a cultivar sua relação com César, mas promete fazer o mesmo. Assim, escreve ele:

Você escreve sobre a extrema afeição de César por nós. Essa afeição da sua parte você deve manter aquecida, da minha parte irei me esforçar para aumentá-la com todos os meios em meu poder. [...] Sua observação, de que você é cada dia mais um favorito de César, é uma fonte de satisfação eterna para mim. ( $Q F R$ III 1).

As afirmações de satisfação com essa nova "amizade" entre o orador e o general são constantes, sendo encontradas em outras cartas, como as enviadas para Ático. Nestas, Marco Túlio diz estar sendo tratado por Júlio César com grande honra, respeito e favores (CÍCERO, IV.17). E considera uma grande vantagem estar, sem dúvidas, na mais alta estima do general (CÍCERO, IV.15). No entanto, essa aparente afinidade deve ser analisada de maneira mais crítica, pois, tendo em vista o conceito de amicitia, até que ponto essa aproximação não seria apenas por interesses políticos de ambos?

Para Adan L. Parison (2014, p. 2), devemos considerar o temor com a segurança das cartas no período. Como já apontado anteriormente, essa era uma das grandes preocupações de Cícero, e para o autor, a maneira que o orador romano escolheu para se proteger disto era não escrever nada que fosse comprometer seus interesses. Assim, não é possível avaliar o grau de sinceridade utilizada por ele em suas cartas, não apenas a César, mas também a outras personalidades. Parison (2014) ainda defende a ideia de que a relação existente entre estas personagens era de uma amicitia pública, que existia enquanto houvesse benefício político entre eles. Este pensamento também é compartilhado pelo historaidor Géza Alfödy (1989, p. 19), em sua tradicional História Social de Roma ele explica que a amiticia era uma ferramenta política muito importante e utilizada em diversas ocasiões na vida pública romana, era ela que 
fundamentava as "relações sociais entre indivíduos de posição semelhante, ou, pelo menos, não muito diferente, no que diz respeito ao poder, prestígio e fortuna" (ALFÖDY, 1989, p. 19).

A aproximação destas duas personagens é crescente, principalmente por meio de amizades em comum e troca de favores, e o fluxo de informações sobre as campanhas de César tornam-se cada vez mais constantes. Acabamos de ver em trecho supracitado que Trebácio, o amigo de Cícero, foi enviado a César para que este pudesse lhe ajudar na carreira militar. O propósito, então, era de que, ao ser enviado à Bretanha, ele pudesse conseguir novas riquezas e sucessos militares. Porém, em outra carta, descobrimos que Trebácio nunca chegou a ir para a Ilha, recebendo comentários irônicos por parte de Cícero por causa disso. ${ }^{6}$ Este não foi o único amigo que Cícero recomendou para César, tal feito voltaria a ocorrer muitas outras vezes.

A maioria das informações sobre o interesse de Cícero na Bretanha vem, obviamente, das cartas trocadas com seu irmão. Estas demonstram um grau de preocupação devido à incursão feita pelo exército. Vejamos como ele se manifesta sobre o tema.

Chego agora ao assunto no qual, talvez, devesse ter sido o primeiro. Quão feliz fiquei ao receber sua carta da Bretanha! Eu temia o oceano, temia a costa da Ilha. As outras partes da empresa eu não subestimo; ainda assim elas inspiram mais esperança do que medo, e é o suspense antes de qualquer verdadeiro alarme que torna-me inquieto. ( $Q F R$. II 15).

Acima, notamos o temor demonstrado pelo orador quanto a travessia do oceano e à Ilha. Isso ocorre, provavelmente, devido a expedição feita anteriormente por César, a qual resultou na devastação de boa parte dos navios romanos, assim como o desastroso desembarcar dos soldados nas praias britânicas. Agora, o que nos é mais interessante é o que parece ser uma ansiedade por parte de Cícero, primeiramente, para obter notícias de seu irmão, mas também de saber sobre a Ilha que, como ele mesmo afirma, "provocam mais esperança do que medo”. Explorar a Bretanha também parecia uma grande oportunidade para a escrita de Quinto, como veremos no trecho a seguir.

Você, no entanto, eu posso ver, possui um esplêndido assunto para descrever, topografia, aspecto natural de coisas e lugares, costumes, raças,

\footnotetext{
${ }^{6}$ Cícero tece, por exemplo, comentários irônicos sobre a falta de coragem de Trebácio. Ver Cícero, ad Fam. VII, 10 .
} 
batalhas, o seu próprio comandante - que temas para sua caneta! ( $Q F R$. II $15)$.

Por meio das cartas também percebemos o interesse, tanto de Quinto quanto de César, nos acontecimentos da $U r b s$.

Quanto aos assuntos públicos, sobre o qual você deseja que Tirão escrever para você, eu os escrevi até agora um pouco mais descuidado do que o habitual, porque eu sabia que todos os eventos, pequenos ou grandes, foram notificados César. ( $Q F R$ III 1).

A partir da leitura deste fragmento, podemos notar que um dos papéis da troca de correspondências era também o de informar aos generais que estavam em campanha sobre os eventos de Roma. É importante também analisarmos a última parte do trecho citado. O fato de todas as informações chegarem à César pode significar, segundo Parison (2014, p. 15), que o general possuía homens que inspecionavam as cartas enviadas e que esta prática teria continuado até a guerra civil.

Nas cartas datadas no final do ano de 54 a.C., percebemos uma mudança na recepção de Cícero acerca das incursões à ilha da Bretanha. O sentimento de esperança e ansiedade passa a um de descaso e até mesmo de chacota com algumas características encontradas naquele local. "Quanto à expedição britânica, concluo pela sua carta que não temos qualquer ocasião nem para temor nem exultação”. (Q FR III 1).

Na epístola acima, enviada a Quinto, Cícero já não aparenta demonstrar o mesmo entusiasmo que nas cartas anteriores. Se em uma das cartas que mencionamos, ele afirmava que as aventuras de César na Bretanha "provocam mais esperança do que medo" (Q FR. II 15), conforme acabamos de ler, o orador já acredita que não há qualquer "ocasião nem para temor nem exultação", o que indica uma ponderação distinta da anterior.

No documento apresentado abaixo, vemos uma menção a um carro de guerra. Trata-se do termo latino essedum, que, de acordo com Nice, é primeiramente relacionado apenas com as carruagens do povo bretão e, posteriormente, passou a possuir um sentido mais amplo. Nas cartas de Cícero, quando este aparece é geralmente num tom de chacota, devido à diferença entre o modo de batalhar de romanos e bretões. 
Na Bretanha foi-me dito que não há ouro ou prata. Se isso acaba por ser o caso, eu aconselho você a capturar uma carruagem de guerra e voltar para nós na primeira oportunidade. (ad Fam. VII, 7)

Na carta enviada à Trebácio Testa, inferimos que um possível motivo para esse desinteresse seja o fato da Ilha não ter gerado frutos como esperado. Como essas invasões geraram não muito mais do que um tributo e alguns escravos, já não existe tantas expectativas quanto à ilha da Bretanha.

Portanto, podemos inferir a partir das cartas que no início das campanhas de César havia um sentimento de esperança de que essa nova conquista pudesse gerar frutos para Roma. Além de ser uma oportunidade de êxito militar e financeiro para algumas personagens, como Trebácio e o próprio Quinto. Com o decorrer dos acontecimentos na Bretanha e o desfecho indeciso das incursões, devido a iminente Guerra Civil, as reações de Cícero tornamse mais pessimistas e o orador já não parece mais acreditar nos benefícios que a Ilha poderia garantir à Urbs. De qualquer maneira, as cartas de Cícero são evidências de que as incursões de César à Bretanha repercutiram no Senado Romano e foram debatidos por políticos importantes deste período do final da República.

\section{CONSIDERAÇÕES FINAIS}

César invadiu a Bretanha por duas vezes, tanto sua primeira incursão em 55 a.C. quando sua frota foi danificada e o general romano teve que suportar o ataque dos Bretões, quanto sua segunda "visita" à Ilha, vitoriosa no ano de 54 a.C., causaram diversas comoções entre a população da cidade de Roma e no próprio Senado Romano. Vimos que a troca de correspondências tinha um papel importante na Antiguidade, pois tratava-se de um dos meios de comunicação mais utilizados no período, ainda mais em tempos de conflitos bélicos em territórios ainda não incorporados ao domínio romano.

Por causa da distância entre Roma e a Bretanha e devido às condições de transporte na época, o envio e o recebimento de informações não eram uma tarefa simples, podendo qualquer correspondência trocada contar ainda com interpelações, o que exigia que os assuntos abordados fossem sabiamente selecionados, no entanto, a partir do acesso à documentação analisada neste artigo foi possível perceber que, apesar das dificuldades, a comunicação ocorria com certa frequência. 
Era parte do costume legislativo e político do período final da República Romana que o Senado fosse avisado acerca das ações que seus generais empreendiam quando enviados por este a outros lugares para resolver pendências nas quais os romanos tinham interesse, o que requeria que qualquer um desses comandantes militares mantivessem contato. Este sistema de comunicação possibilitava a troca de informação sobre diversos temas, por isso, nem César era alheio ao que ocorria em Roma, sendo avisado de alguns acontecimentos importantes, inclusive da movimentação política de seus adversários, muito menos as pessoas que ficaram na Urbs ignoravam suas ações. Foi isto que tentamos demonstrar neste artigo, que as incursões de César à Bretanha repercutiram no Senado Romano, algo que pudemos perceber analisando as cartas de Cícero.

\section{REFERÊNCIAS BIBLIOGRÁFICAS}

\section{A) FONTES UTILIZADAS}

CÍCERO, M. T. The Letters of Cicero, Volume 1 The Whole Extant Correspodence in Chronological Order. Trad. Evelyn S. Shuckburgh. April, 2007.

Epistulae ad Quintum Fratem. In. SHUCKBURGH, E. S. Letters of Cicero, Volume 1 The Whole Extant Correspodence in Chronological Order. April, 2007.

Epistulae ad Atticum. In. SHUCKBURGH, E. S. Letters of Cicero, Volume 1 The Whole Extant Correspodence in Chronological Order. April, 2007.

Epistulae ad Familiares. In. SHUCKBURGH, E. S. Letters of Cicero, Volume 1 The Whole Extant Correspodence in Chronological Order. April, 2007.

APPIAN, Roman History, Trans. Horace White. Londres, Harvard University Press, 1958 (The Loeb Classical Library).

CASSIUS DIO, Roman History. English translation by Earnest Cary. London: William Heinemann,1961. v.9 ( The Loeb Classical Library ).

PLUTARCO, Vidas Paralelas: Vida de César. Trad. CHAVES, Carlos. São Paulo: Editora Edameris, 2008.

SALÚSTIO, Obra Completa, trad. e introd. Agostinho da Silva. Lisboa: Livros Horizonte, 1974.

SUETÔNIO, A Vida dos Doze Césares. São Paulo: Martin Claret, 2006. 


\section{B) OBRAS GERAIS}

ALFÖDY, Géza. História Social de Roma. Lisboa: Presença, 1989.

BOURDIEU, Pierre. A Ilusão Biográfica. In. AMADO, Janaína; FERREIRA, Marieta de Moraes (Orgs.). Usos e abusos da história oral. Rio de Janeiro: FGV, 1996. p. 183-191.

CARDOSO, Ciro Flamarion. História e poder: uma nova história política? In. CARDOSO, Ciro Flamarion; VAINFAS, Ronaldo (Orgs.). Novos Domínios da História. Rio de Janeiro: Elsevier, 2012. p. 37-54.

DA ROSA, Claudia Beltrão. Campos de Batalha, Espaços de Guerra: Os Commentarii de Bello Gallico de Caio Júlio César. Brathair: Edição Especial 1, 2007. p. 38-45.

. Retórica e Ação Política: A Complexio no Pro Roscio Amerino de Marco Túlio Cícero. Tempo, Rio de Janeiro, $\mathrm{n}^{\circ}$ 18, p. 125-145.

De haruspicum responso: religião e política em Cícero. Mirabilia, 03, Dec, 2003.

Prudentia e Prudens em Cícero: Religião, Jurisprudência e os Poderes do Magistrado. R. EMERJ, Rio de Janeiro, v. 17, n. 64, p. 49 - 66, Jan. - abr. 2014.

DEISSMANN, Adolf. Apud: SOARES, Carolline da Silva. Gênero Epistolar na Antiguidade: a Importância das Cartas de Cipriano para a História do Cristianismo Norte Africano (século iii d.c.). Revista História e Cultura, Franca-SP, v.2, n.3 (Especial), p.199-215, 2013.

DRUCKENMILLER, Jenny D. Cicero's Letters and Roman Epistolary Etiquette. Eugene: University of Oregon Press. 2007.

GUARINELLO, Norberto. Prefácio. In. CÂNFORA, Luciano. Júlio César: o ditador democrático. São Paulo: Estação Liberdade, p.11-16. 2002.

GONÇALVES, A. T. M. Diversidade Étnica no Império Romano: O Caso dos Bretões. Revista Phoînix. Rio de Janeiro, v. 8, p. 15-23, 2002.

DI MESQUITA, Fabrício Dias Gusmão. Atividade Epistolar no Mundo Antigo: Relendo as Cartas Consolatórias de Sêneca. História Revista, Goiânia, v. 15, n. 1, p. 31-53, jan./jun. 2010.

MENDES, Norma Musco. Roma Republicana. São Paulo: Editora Ática S.A., 1988.

NICE, Alex. C. Trebatius Testa and the British Charioteers: The Relationship of Cic. Ad Fam. 7.10.2 To Caes. BG 4.25 And 33. ACTA CLASSICA XLVI (2003) 71-96.

PARISON, Adam L. Cicero and Caesar: A Turbulent Amicitia. 2014. 98 p. Dissertação (História) East Carolina University, East Carolina, June, 2014.

RANKE, Leopold Von. Geschichte der romanischen und germanischen Völker von 1494 bis 1535. Reimer: Leipzig, 1824. 
SCHMIDT, Benito Bisso. Biografia e regimes de historicidade. Revista MÉTIS: história \& cultura - v. 2, n. 3, jan./jun. p.61, 2003.

SOARES, Carolline da Silva. O Gênero Epistolar na Antiguidade: a Importância das Cartas de Cipriano para a História do Cristianismo Norte Africano (século iii d.c.). Revista História e Cultura, Franca-SP, v.2, n.3 (Especial), p.199-215, 2013.

VÁRZEAS, Marta. Introdução In. Plutarco, Vidas Paralelas - Demóstenes e Cícero. Tradução do grego, introdução e notas: Marta Várzeas. Coimbra: Centro de Estudos Clássicos e Humanísticos. Edição: 1ª/2010, p. 82.

WHITE, Peter. Cicero in Letters: Epistolary Relations of the Late Republic. Oxford: Oxford University Press, 2010. 